Computer Optics and Nanophotonics

\title{
Analysis of activity of the scientific journal Computer Optics
}

\author{
Kolomiets E.I. \\ Samara State Aerospace University
}

\begin{abstract}
The author analyzes the significance of the journal Computer Optics for the development of science in Russia. A particular attention is given to research areas covered and journal publications that attracted a special interest of the research community in the fields of diffractive optics and nanophotonics, optical information technology, pattern recognition, and image processing. The author gives credit to the efforts of the editorial staff that contributed to the Journal success and outlines prospects of the journal development.
\end{abstract}

Keywords: scientific journal, the editorial board, optical information technology, image processing, computer vision, diffractive nanophotonics, micro- and nanotechnologies

Citation: Kolomiets EI. Analysis of activity of the scientific journal Computer Optics. Proceedings of Information Technology and Nanotechnology (ITNT2015), CEUR Workshop Proceedings, 2015; 1490: 138-150. DOI: 10.18287/1613-0073-2015-1490-138-150

\section{Introduction}

This year we celebrate the 40th anniversary of the Computer Science Faculty of Samara State Aerospace University (National Research University) (SSAU) and the 70th anniversary of the chief editor of the scientific journal Computer Optics Professor V.A. Soifer. Computer Optics is published jointly by the Image Processing Systems Institute of the RAS (IPSI RAS, scientific lieder of IPSI RAS is Prof. V.A. Soifer) and Computer Science Faculty of SSAU. This is a good occasion to look back at the journal accomplishments and give credit to the editorial staff for essential efforts they have contributed to the Journal success.

\section{Background and prerequisites}

Fundamental research findings jointly made at the turn of the 60-70s of the last century by the research teams from Moscow and Kuibyshev (presently Samara) headed by academician A.M. Prokhorov, professor I.N. Sisakyan, and professor V.A. Soifer enabled the design of new classes of optical elements [1 -6], making it possible to address problems going beyond the scope of classical optics. The novel optical elements were given the name diffractive optical elements (DOEs), with elements intended for performing specific tasks termed as laser light focusators [1 - 
3], modans [4], Bessel-optics elements [5], compensators/equalizers [6], and so on. Some of the above-listed terms, e.g. the term focusator proposed by academician A.M. Prokhorov, have been adopted not only in Russia but also internationally [7 10]. As the research community embraced the significance of the new findings, it became evident that we witness the emergence of a new field of research at the interface of information technology, laser physics, optics, and microelectronics, having become known as Diffractive Computer Optics. Thus, a demand arose for a scientific periodical that would promptly peer-review and publish articles dealing with the new, rapidly developing area. In May 1986, the decision of the kickoff meeting on Computer Optics (the city of Zvenigorod) to start the publication of a new journal was approved by the Russian science leadership. In 1987, the first issue of the international scientific collection Computer Optics with a subtitle Physical Principles was published.

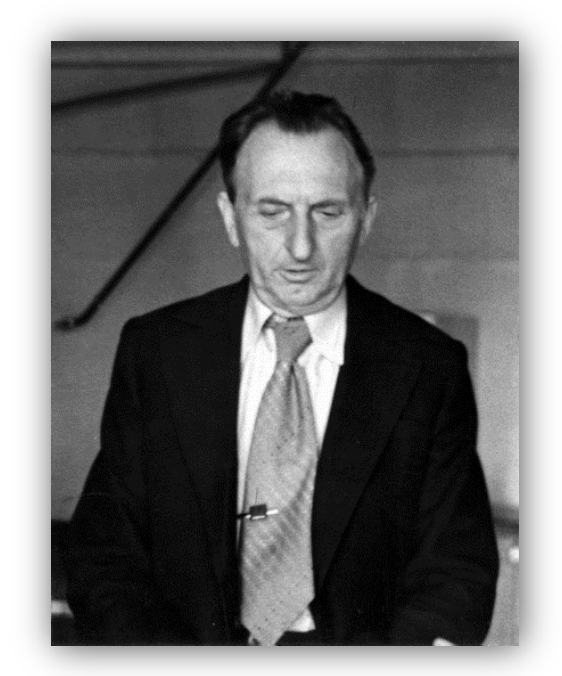

Fig. 1. - Academician Alexander Mikhailovich Prokhorov (1916-2002)

\section{Kick-start beginning}

Among the co-founders of Computer Optics, there were the International Center for Scientific and Technical Information (ICSTI), Institute of General Physics of the USSR Academy of Sciences, Institute of Information Transmission Problems of the USSR Academy of Science, with the ICSTI also acting as a publisher. The publication was funded as part of the information support of the complex program of scientific and technical progress of member-states of the Council for Mutual Economic Assistance (CMEA). In the initial years, the collection of papers Computer Optics was edited by academicians Ye.P. Velikhov and A.M. Prokhorov. The first issues were compiled by I.N. Sisakyan, V.A. Soifer, R.V. Matveeva, S.A. Orekhov, A.M. Kostin, and V.A. Danilov, with the essential contribution made by scientists of Kuibyshev Aviation Institute (presently, SSAU). 
In the Foreword to the very first issue, academician Ye.P. Velikhov, in particular, wrote [11], 'Truly revolutionary has been the role played by the computer in designing totally new classes of optical elements like light focusators, wavefront correctors, modal content analyzers, to name just a few. In computer optics, the computer serves a wide variety of functions from solving the inverse problem of diffraction and conducting numerical simulations to numerically controlling the automated machinery, interpreting and visualizing the experimental data, designing elements with optimal characteristics, to developing databanks, and so on'. The following words by Ye.P. Velikhov have recently become particularly relevant, '...computer optics is not just computers in optics, but optics in computers as well. A number of optical elements intended for information processing and capable of addressing a broad range of interesting problems have been already designed'. Actually, advanced components for diffractive nanophotonics, such as resonant diffraction gratings [12 - 14], nanocavities [15 - 18], and other devices [19] are able to perform analog operations of the differentiation and integration of optical signals and, when combined with diffractive optics elements such as beam splitters [20] and multi-purpose DOEs [21 - 22], form a basis for the development of analog optical computers [19]. Taking a retrospective view at the progress made on the way from the first diffraction grating to diffractive optics elements, Nobel Prize laureate A.M. Prokhorov noted [23], 'Flat optics took a drastic turn, essentially resulting in the advent of a new field of diffractive optics, when focusators of laser light were designed in 1980. The very first focusator was created jointly by researchers of the Institute of General Physics of the USSR Academy of Sciences and Kuibyshev Aviation Institute. Before long, mathematicians from the Moscow University became actively involved in the work. Over a short time span of less than 10 years, a variety of diffractive optics elements were designed and diffractive optics was formed as a new research area ...'

Great contribution to the creation of initial issues of Computer Optics collection was made by Professor Iosif Norairovich Sisakyan [24]. In particular, the article entitled 'Computer Optics. Achievements and Challenges' written jointly by I.N. Sisakyan and V.A. Soifer [25] became a hit publication of the first issue, having determined the vector of development in the field for decades to come. Among the contributors to the first issue, there were leading soviet researchers active in computer optics in those years, such as A.M. Prokhorov, M.A. Golub, G.I. Greysukh, A.V. Goncharskiy, V.A. Danilov, N.L. Kazanskiy, B.E. Kinber, D.D. Klovsky, S.G. Kryvoshlykov, V.V. Popov, S.A. Stepanov, A.B. Shvartzburg, S.M. Shirokov, and others. A number of publications included in the first issue opened up new directions of computer/diffractive optics. For instance, synthesis of optical elements and systems intended to generate desired radiation directivity diagrams [26] has led to the design of various lighting devices which were proposed both in Computer Optics [27 - 31] and in leading international scientific journals [32-35]. Diffraction analysis of the focusing elements by means of numerical simulation [36] went on to be actively developed in follow-up publications [37 - 45]. Great interest was attracted by an article reporting on techniques for focusators design [46]. In the follow-up research, those techniques were essentially improved and extended onto new focal regions of interest [47-52]. An important research area concerned with generating a 
diffraction microrelief of optical elements was first proposed in Ref. [53] and was further developed in numerous publications in Russian [54 - 60] and foreign [61 - 63] Editions.

The first issue of Computer Optics became internationally recognized, having attracted interest from "Pergamon Press" that published two volumes of the journal in English in the years 1989-1990 (Vol. 1, N 1, 1989; Vol. 2, N 1 \& N 2, 1990) with world-wide distribution (with cities like Oxford, New York, Beijing, Frankfurt, San Paolo, Sidney, Tokyo, Toronto indicated on the journal cover). Volume I in English was compiled on the basis of the first Russian issue, and Volume II included papers from Russian issues 3 and 4.

Following I.N. Sisakyan's appointment to the position of director of Central Design Bureau of Unique Instrumentation (CDB UI) of the USSR Academy of Sciences, the list of co-founders changed. Since 1988 (issues 3 -9), the ICSTI and the CDB UI of the USSR Academy of Sciences acted as the collection's co-founders. Especially noteworthy in issue 3 is a paper [64] devoted to the technological applications of focusators, which laid the basis for a new direction of diffractive optics that was thriving in the subsequent years [65-68]. This research topic was among others which allow a group of SSAU researchers (V.A. Soifer, V.P. Shorin, V.A. Barvinok, V.I. Mordasov, V.I. Bogdanovich and A.G. Zidulko) jointly with I.N. Sisakyan to receive the RF State Prize for outstanding achievements in science and technology in 1992.

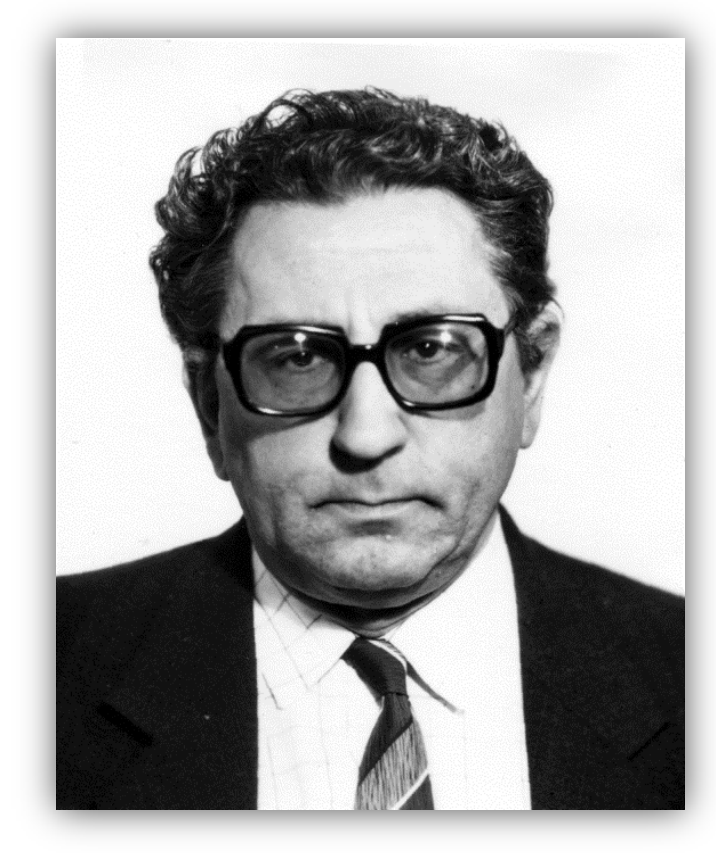

Fig. 2. - Professor Iosif Norairovich Sisakyan (1938-1995) 


\section{Help from Samara}

Collapse of the USSR followed by the disintegration of the CMA, temporarily brought the publication of Computer Optics to stop in 1992, which was associated with the termination of the Complex program of scientific \& technical progress of the CMA member-states. Being the RAS establishment, the CDB UI was run on the selffinancing basis, not having a financing from the state budget. With the collapse of the Soviet Union, the contract-based financing of scientific research was drastically decreased. In those circumstances, in 1992 the research group headed by Prof. V.A. Soifer had to take care of the financial back-up of the publication, with the SSAU having become a third cosponsor of the collection. 1992 saw the publication of a twin issue 10-11 and issue 12, with issue 13 published in 1993. Unfortunately, since those years were marked by the growth of publication and distribution costs significantly exceeding the financing of scientific research, Computer Optics was not published in 1994.

However, in 1995, thanks to the assistance of academician N.A. Kuznetsov, director of Institute for Information Transmission Problems of the Russian Academy of Sciences (IITP of the RAS), and Dr. N.S. Merzlyakov, the head of digital optics sector at the IITP of the RAS, the financing was obtained, which enabled the publication of a two-part twin issue 14-15. Alongside the ICSI, SSAU, and CDB UI of the RAS, the IITP of the RAS and Image Processing Systems Institute of the Russian Academy of Sciences (IPSI of the RAS, before 1993 known as Samara branch of CDB UI of the RAS) also acted as a cosponsor of twin issue 14-15 of Computer Optics. Twin 14-15 issue became the last to be compiled and edited with participation of I.N. Sisakyan, who soon untimely passed away.

Starting from issue 16 commemorating I.N. Sisakyan, the collection starts to be entirely published in Samara, with the ICSTI, SSAU, and IPSI of the RAS acting as cosponsors.

\section{Journal}

Even though Computer Optics is no longer published in English, it acquires ever growing recognition in the scientific community. On October 17, 2001 the collection was included into the list of RF Higher-Certifying-Commission-recommended scientific periodicals for publication of research papers relating to key findings of doctoral dissertations. The results published in Computer Optics later formed the basis of doctoral dissertations by V.M. Chernov, L.L. Doskolovich, A.I. Danilin, Ye.G. Ezhov, V.A. Fursov， D.L. Golovashkin， O.V. Goryachkin， N.Yu. Ilyasova, V.V. Ivakhnik, N.L. Kazanskiy, S.V. Karpeev, S.I. Kharitonov, S.N. Khonina, A.G. Khramov, A.A. Kovalev, V.A. Kolpakov, A.V. Kupriyanov, I.V. Minin, O.V. Minin, S.P. Murzin, V.V. Myasnikov, V.S. Pavelyev, A.G. Poleschuk, S.B. Popov, V.V. Sergeev, R.V. Skidanov, S.A. Stepanov, A.V. Volkov, and others.

Since 2007 the collection has been a quarterly scientific journal jointly published by the SSAU and IPSI of the RAS. The Editorial Board includes three academicians of the RAS (Yu.I. Zhuravlev, V.Ya. Panchenko and I.A. Scherbakov), three corresponding members of the RAS (S.Yu. Zheltov, B.V. Kryzhanovsky and V.A. Soifer), six Doctors of Science (N.L. Kazanskiy, V.V. Korlyar, V.S. Pavelyev, 
V.V. Sergeev, S.N. Khonina, and V.M. Chernov), as well as scientists from Germany (professor Richard Kowarschik of Friedrich Shieller University, Jena), India (professor Kehar Singh), China (academician Jin Guofan of Tsinghua University, Beijing), and Finland (professor Jari Turunen of Joensuu University). On 22 March 2007, V.A. Soifer was appointed Editor-in-Chief of the journal of Computer Optics by Resolution N 2-8 of the RAS' Information Technologies and Computing Systems department. V.A. Soifer outlines [69] the Journal's strategic direction, the scope of research topics to be covered, also dealing with staffing the Editorial Board. The process of reviewing the submitted manuscripts on optical information technologies and diffractive nanophotonics is supervised by professor S.N. Khonina, the Editorial Board's secretary, on image processing and geo-information technologies - by V.M. Chernov, Doctor of Physics \& Math. Credit for big work associated with preparation of the Journal for publication should be given to Ya.Ye. Takhtarov, issue editor, S.V. Smagin, M.A. Vakhe, and Yu.N. Litvinova. The Journal is published under financial support of the Samara Region government.

The scope of research topics covered by the Journal has been extended, embracing areas such as plasmonics and diffractive nanophotonics [70-79], geo-information technologies [80 - 84], computer vision [85 - 87], interpretation and understanding of nanoscale images [88-92], diffractive X-ray optics [93-94], optical computations [12 - 16], analysis of hyperspectral data [95 - 98], the development of Hyper-spectral instruments for Earth remote sensing [99 - 102], new types of diffraction conditioners beams with unique properties [103-105], sharp focusing [106-108]. Further contributing to the development of the above-mentioned new topics, the journal authors have published corresponding articles in the leading international journals [109-120]. Promptly responding to emerging research areas and following the cutting-edge scientific trends enables Computer Optics to be actively developing, winning the growing recognition in the research community. Online versions of the Journal articles are in open access at www.computeroptics.smr.ru, and can also be found on the scientific e-library website at eLIBRARY.RU. According to the e-library statistics, most widely cited are publications [55-56, 66, $121-127]$.

\section{Conclusion}

The fact that since 2012 Computer Optics has been abstracted and indexed in international databases of scientific publications, such as SCOPUS and Compendex, can be considered a significant success of the Journal, which is lacking the full-text English version. This enabled Computer Optics to be included in the list of scientific periodicals recommended by the Higher Certifying Commission of the RF Ministry of Science and Education for publication of key research findings of doctoral dissertations. Synergy of different topics covered by the Journal, which integrates achievements of diffractive optics, diffractive nanophotonics, and digital image processing, is critical for the progress of the world science, also forming the basis for further success of the scientific periodical. The goal of the current stage of the Journal development is its inclusion in the Web of Science Core Collection. 


\section{References}

1. Golub MA, Karpeev SV, Prokhorov AM, Sisakyan IN, Soifer VA. Focusing light into a specified volume by computer synthesized holograms. Soviet Technical Physics Letters, 1981; 7(10): 618-623.

2. Golub MA, Degtyarova VP, Klimov AN, Popov VV, Prokhorov AM, Sisakyan IN, Soifer VA. Machine synthesis of focusing elements for $\mathrm{CO}_{2}$-laser. Soviet Technical Physics Letters, 1982; 8(8): 449-451. [in Russian]

3. Danilov VA, Popov VV, Prokhorov AM, Sagatelyan DM, Sisakyan IN, Soifer VA. Synthesis of optical elements, that create focal free-form line. Soviet Technical Physics Letters, 1982; 8(13): 810-815. [in Russian]

4. Golub MA, Prokhorov AM, Sisakyan IN, Soifer VA. Synthesis of spatial filters for investigation of the transverse mode composition of coherent radiation. Soviet Journal of Quantum Electronics, 1982; 12(9): 1866-1868.

5. Bereznyi AE, Prokhorov AM, Sisakyan IN, Soifer VA. Bessel-optics. Dokl. Akad. Nauk USSR, 1984; 274(3): 605-608. [in Russian]

6. Golub MA, Kazanski NL, Sisakjan IN, Soifer VA. Computer generated optical elements for optical testing. Proceedings of SPIE, 1990; 1319: 635-636.

7. Golub MA, Sisakyan IN, Soifer VA. Infra-red Radiation Focusators. Optics and Lasers in Engineering, 1991; 15(5): 297-309.

8. Doskolovich LL, Kazanskiy NL, Kharitonov S.I, Usplenjev GV. Focusators for laserbranding. Optics and Lasers in Engineering, 1991; 15(5): 311-322.

9. Kazanskiy NL, Soifer VA. Diffraction investigation of geometric-optical focusators into a segment. Optik - International Journal for Light and Electron Optics, 1994; 96(4): 158-162.

10. Kazanskiy NL, Kharitonov SI, Soifer VA. Application of a pseudogeometrical optical approach for calculation of the field formed by a focusator. Optics \& Laser Technology, 1996; 28(4): 297-300.

11. Velikhov EP. Foreword. Computer Optics, 1989; 1(1): 1.

12. Golovastikov NV, Bykov DA, Doskolovich LL, Soifer VA. Temporal differentiation of optical signals in reflection using resonant gratings. Computer Optics, 2012; 36(2): 151157. [in Russian]

13. Golovastikov NV, Bykov DA, Doskolovich LL, Soifer VA. Resonant diffraction gratings for differentiation of optical signals in reflection and transmission. Computer Optics, 2013; 37(2): 138-145. [in Russian]

14. Golovastikov NV, Bykov DA, Doskolovich LL. Spatial integration of optical beams using phase-shifted Bragg grating. Computer Optics, 2014; 38(3): 372-376. [in Russian]

15. Kazanskiy NL, Serafimovich PG, Khonina SN. Use of photonic crystal resonators for differentiation of optical impulses in time. Computer Optics, 2012; 36(4): 474-478. [in Russian]

16. Kazanskiy NL, Serafimovich PG. Using photonic crystal nanobeam cavities for integration of optical signal. Computer Optics, 2014; 38(2); 181-187. [in Russian]

17. Kazanskiy NL, Serafimovich PG, Khonina SN. Use of photonic crystal cavities for temporal differentiation of optical signals. Optics Letters, 2013; 38(7): 1149-1151.

18. Kazanskiy NL, Serafimovich PG. Coupled-resonator optical wave-guides for temporal integration of optical signals. Optics Express, 2014; 22(11): 14004-14013.

19. Gavrilov AV, Soifer VA. Prospects of optical analog computer development. Computer Optics, 2012; 36(2): 140-150. [in Russian]

20. Kazanskiy NL, Skidanov RV. Binary beam splitter. Applied Optics, 2012; 51(14): 26722677. 
21. Golub MA, Doskolovich LL，Kazanskiy NL，Kharitonov SI，Soifer VA. Computer generated diffractive multi-focal lens. Journal of Modern Optics, 1992; 39(6): 1245-1251.

22. Soifer VA, Doskolovich LL, Kazanskiy NL. Multifocal diffractive elements. Optical Engineering, 1994; 33(11): 3610-3615.

23. Prokhorov AM. Foreword. Computer Optics, 1989; 1(1): 2.

24. Soifer VA. Computer Optics in the works by Professor I.N. Sisakyan. Computer Optics, 2002; 24: 5-10. [in Russian]

25. Sisakyan IN, Soifer VA. Computer Optics: achievements and problems. Computer Optics, 1989; 1(1): 3-12.

26. Golub MA, Kazanskii NL, Prokhorov AM, Sisakyan IN, Soifer VA. Synthesis of optical antennae. Computer Optics, 1989; 1(1): 25-28. [in Russian]

27. Kazanskiy NL, Soifer VA, Kharitonov SI. Modeling of lighting devices with DOE. Computer Optics, 1995; 14-15(2): 107-116. [in Russian]

28. Doskolovich LL, Kazanskiy NL, Kharitonov SI. Design of DOE-aided lighting devices. Computer Optics, 1998; 18: 91-96. [in Russian]

29. Volkov AV, Kazanskiy NL, Usplenjev GV. Experimental study of lighting devices based on diffractive optical elements. Computer Optics, 1999; 19: 137-142. [in Russian]

30. Dmitriev AYu, Doskolovich DL, Doskolovich LL, Kazanskiy NL. Analytic design of refractive optical elements generating one-parameter directivity diagram. Computer Optics, 2014; 38(2): 207-212. [in Russian]

31. Doskolovich LL, Moiseev MA, Kazanskiy NL. On using a supporting quadric method to design diffractive optical elements. Computer Optics, 2015; 39(3): 339-346. [in Russian]

32. Doskolovich LL, Kazanskiy NL, Soifer VA, Kharitonov SI, Perlo P. A DOE to form a line-shaped directivity diagram. Journal of Modern Optics, 2004; 51(13): 1999-2005.

33. Doskolovich LL, Kazanskiy NL, Bernard S. Designing a mirror to form a line-shaped directivity diagram. Journal of Modern Optics, 2007; 54(4): 589-597.

34. Doskolovich LL, Dmitriev AYu, Moiseev MA, Kazanskiy NL. Analytical design of refractive optical elements generating one-parameter intensity distributions. J. Opt. Soc. Am. A, 2014; 31(11): 2538-2544.

35. Aslanov ER, Doskolovich LL, Moiseev MA, Bezus EA, Kazanskiy NL. Design of an optical element forming an axial line segment for efficient LED lighting systems. Optics Express, 2013; 21(23): 28651-28656.

36. Kazanskii NL. Correction of focuser phase function by computer-experimental methods. Computer Optics, 1989; 1(1): 69-73.

37. Golub MA, Kazanskii NL, Sisakyan IN, Soifer VA, Kharitonov SI. Diffraction calculation for an optical element which focuses into a ring. Optoelectronics, Instrumentation and Data Processing, 1987; 6: 7-14.

38. Golub MA, Kazanskii NL, Sisakyan IN, Soifer VA. Computational experiment with plane optical elements. Optoelectronics, Instrumentation and Data Processing, 1988; 1: 78-89.

39. Kazansky NL. Numerical experiment with a Fresnel lens. Computer Optics, 1990; 2(1): $17-21$.

40. Kazanskiy NL, Kharitonov SI. Transmission of space-limited broadband symmetrical radial pulses focused through a thin film. Computer Optics, 2012; 36(1): 4-13. [in Russian]

41. Kazanskiy NL, Kharitonov SI, Khonina SN. Joint solution of the Klein-Gordon and Maxwell's equations. Computer Optics, 2012; 36(4): 518-526. [in Russian]

42. Kazanskiy NL, Kotlyar VV, Soifer VA. Computer-aided design of diffractive optical elements. Optical Engineering, 1994; 33(10): 3156-3166.

43. Doskolovich LL, Kazanskiy NL, Soifer VA. Comparative analysis of different focusators focusing into segment. Optics and Laser Technology, 1995; 27(4): 207-213. 
44. Doskolovich LL, Kazanskiy NL, Soifer VA, Tzaregorodtzev AYe. Analysis of quasiperiodic and geometric optical solutions of the problem of focusing into an axial segment. Optik - International Journal for Light and Electron Optics, 1995; 101(2): 37-41.

45. Kazanskiy NL, Serafimovich PG. Cloud Computing for Nanophotonic Simulations. Lecture Notes in Computer Science, 2013; 7715: 54-67.

46. Danilov VA, Kinber BE, Shishlov AV. Theory of coherent focusers. Computer Optics, 1989; 1(1): 29-37.

47. Doskolovich LL, Golub MA, Kazanskiy NL, Khramov AG, Pavelyev VS, Seraphimovich PG, Soifer VA, Volotovskiy SG. Software on diffractive optics and computer generated holograms. Proceedings of SPIE, 1995; 2363: 278-284.

48. Doskolovich LL, Kazanskiy NL, Kharitonov SI, Soifer VA. A method of designing diffractive optical elements focusing into plane areas. Journal of Modern Optics, 1996; 43(7): 1423-1433.

49. Doskolovich LL, Kazanskiy NL, Perlo P, Repetto P, Soifer VA. Direct two-dimensional calculation of binary DOEs using a non-binary series expression approach. International Journal of Optoelectronics, 1996; 10(4): 243-249.

50. Soifer VA, Kazanskiy NL, Kharitonov SI. Synthesis of a binary DOE focusing into an arbitrary curve using the electromagnetic approximation. Optics and Lasers in Engineering, 1998; 29(4-5): 237-247.

51. Doskolovich LL, Kazanskiy NL, Soifer VA, Perlo P, Repetto P. Design of DOEs for wavelength division and focusing. Journal of Modern Optics, 2005; 52(6): 917-926.

52. Bezus EA, Doskolovich LL, Kazanskiy NL. Low-scattering surface plasmon refraction with isotropic materials.Optics Express, 2014; 22(11): 13547-13554.

53. Popov VV. Materials and methods for flat optical elements. Computer Optics, 1989; 1(1): 125-128.

54. Volkov AV, Kazanskiy NL, Soifer VA, Solovyov VS. Technology for forming continuous microrelief of diffractive optical elements. Computer Optics, 1997; 17: 91-93. [in Russian]

55. Volkov AV, Kazanskiy NL, Rybakov OE. Investigation of plasma etching technology for producing multilayer diffractive optical elements. Computer Optics 1998; 18: 127-130. [in Russian]

56. Volkov AV, Kazanskiy NL, Rybakov OE. Development of technology for creation of diffractive optical elements with submicron dimensions of the relief in the silicon wafer. Computer Optics, 1998; 18: 130-133. [in Russian]

57. Volkov AV, Moiseev OYu, Poletaev SD, Chistyakov IV. Application of thin molybdenum films in contact masks for manufacturing the micro-relief of diffractive optical elements. Computer Optics, 2014; 38(4): 757-762. [in Russian]

58. Kazanskiy NL, Kolpakov VA, Kolpakov AI. Anisotropic etching of $\mathrm{SiO}_{2}$ in high-voltage gas-discharge plasmas. Russian Microelectronics, 2004; 33(3): 169-182.

59. Abulkhanov SR, Kazanskii NL, Doskolovich LL, Kazakova OY. Manufacture of diffractive optical elements by cutting on numerically controlled machine tools. Russian Engineering Research, 2011; 31(12): 1268-1272.

60. Bezus EA, Doskolovich LL, Kazanskiy NL. Interference pattern generation in evanescent electromagnetic waves for nanoscale lithography using waveguide diffraction gratings. Quantum Electronics, 2011; 41(8) 759-764.

61. Volkov AV, Kazanskiy NL, Moiseev OJu, Soifer VA. A method for the diffractive microrelief forming using the layered photoresist growth. Optics and Lasers in Engineering, 1998; 29(4-5): 281-288. 
62. Pavelyev VS, Borodin SA, Kazanskiy NL, Kostyuk GF, Volkov AV. Formation of diffractive microrelief on diamond film surface Optics \& Laser Technology, 2007; 39(6): 1234-1238.

63. Kazanskiy NL, Kolpakov VA, Podlipnov VV. Gas discharge devices generating the directed fluxes of off-electrode plasma. Vacuum, 2014; 101: 291-297.

64. Sisakyan IN, Shorin VP, Soifer VA, Mordasov VI, Popov VV. Technological capabilities of focusators in laser-induced material processing. Computer Optics, 1990; 2(1): 85-87.

65. Doskolovich LL, Kazanskiy NL, Mordasov VI, Murzin SP, Kharitonov SI. Investigation of the optical transmission control systems for high energy. Computer Optics, 2002; 23: 40-43. [in Russian]

66. Kazanskiy NL, Murzin SP, Tregub VI. Optical system for realization of selective laser sublimation of metal alloy components. Computer Optics, 2010; 34(4): 481-486. [in Russian]

67. Murzin SP. Method of composite nanomaterials synthesis under metal/oxide pulseperiodic laser treatment. Computer Optics, 2014; 38(3): 469-475. [in Russian]

68. Kazanskiy NL, Murzin SP, Osetrov Ye L, Tregub VI. Synthesis of nanoporous structures in metallic materials under laser action. Optics and Lasers in Engineering, 2011; 49(11): 1264-1267.

69. Soifer VA. Quo vadis. Computer Optics, 2014; 38(4): 589.

70. Soifer VA. Nanophotonics and diffractive optics. Computer Optics, 2008; 32(2): 110-118. [in Russian]

71. Bezus EA, Doskolovich LL, Kadomin II, Kazanskiy NL, Civera P, Pizzi M. Generating varying-period interference patterns of surface plasmons by diffraction gratings. Computer Optics, 2008; 32(3): 234-237. [in Russian]

72. Bezus EA, Doskolovich LL，Kazanskiy NL，Soifer VA，Kharitonov SI， Pizzi M, Perlo P. The design of diffractive optical elements to focus surface plasmons. Computer Optics, 2009; 33(2): 185-192. [in Russian]

73. Soifer VA, Kotlyar VV, Doskolovich LL. Diffractive optical elements in nanophotonic devices. Computer Optics, 2009; 33(4): 352-368. [in Russian]

74. Kazanskiy NL, Serafimovich PG, Popov SB, Khonina SN. Using guided-mode resonance to design nano-optical spectral transmission filters. Computer Optics, 2010; 34(2): 162-168. [in Russian]

75. Kazanskiy NL, Serafimovich PG, Khonina SN. Optical nanoresonator on a ridge of crossing photonic-crystal waveguides. Computer Optics, 2011; 35(4): 426-431. [in Russian]

76. Egorov AV, Kazanskiy NL, Serafimovich PG. The use of coupled photonic crystal cavities for increasing of sensor sensitivity. Computer Optics, 2015; 39(2): 158-162. [in Russian]

77. Kazanskiy NL, Khonina SN, Kharitonov SI. The perturbation theory for Schroedinger equation in the periodic environment in momentum representation. Computer Optics, 2012; 36(1): 21-26. [in Russian]

78. Khonina SN, Volotovskiy SG, Kharitonov SI, Kazanskiy NL. Calculation of the power spectrum of complex low-dimensional heterostructures in the electric field. Computer Optics, 2012; 36(1): 27-33. [in Russian]

79. Kazanskiy NL, Serafimovich PG, Khonina SN. Enhancement of spatial modal overlap for photonic crystal nanocavities. Computer Optics, 2012; 36(2): 199-204. [in Russian]

80. Zherdev DA, Kazanskiy NL, Fursov VA, Kharitonov SI. Electromagnetic field scattering simulation from anthropogenic objects on underlying surface. Computer Optics, 2013; 37(1): 91-98. [in Russian] 
81. Sergeyev VV, DenisovaAYu. Iterational method for piecewise constant images restoration with an a priori knowledges of image objects boundaries. Computer Optics, 2013; 37(2): 239-243. [in Russian]

82. Fursov VA, Goshin YeV. Information technology for digital terrain model reconstruction from stereo images. Computer Optics, 2014; 38(2): 335-342. [in Russian]

83. Zherdev DA, Kazanskiy NL, Fursov VA. Object recognition by the radar signatures of electromagnetic field scattering on base of support subspaces method. Computer Optics, 2014; 38(3): 503-510. [in Russian]

84. Zherdev DA, Kazanskiy NL, Fursov VA. Object recognition in radar images using conjugation indices and support subspaces. Computer Optics, 2015; 39(2): 255-264. [in Russian]

85. Kazansky NL, Popov SB. A machine vision system for counting the number of gel particles in a polymer solution. Computer Optics, 2009; 33(3): 325-331. [in Russian]

86. Kazanskiy NL, Popov SB. The distributed vision system of the registration of the railway train. Computer Optics, 2012; 36(3): 419-428. [in Russian]

87. Kazanskiy NL, Khonina SN, Skidanov RV, Morozov AA, Kharitonov SI, Volotovskiy SG. Formation of images using multilevel diffractive lens. Computer Optics, 2014; 38(3): 425-434. [in Russian]

88. Borodin SA, Volkov AV, Kazanskiy NL. An automated device for assessing the substrate purity based on the dynamics of a surface fluid droplet. Computer Optics, 2005; 28: 69-75. [in Russian]

89. Babin SV, Doskolovich LL, Kadomin II, Kadomina EA, Kazanskiy NL. Characterization of a trapezoidal diffraction grating profile based on polynomial approximations of the reflected field. Computer Optics, 2009; 33(2): 156-161. [in Russian]

90. Soifer VA, Kupriyanov AV. Analysis and recognition of the nanoscale images: conventional approach and novel problem statement. Computer Optics, 2011; 35(2): 136144. [in Russian]

91. Kupriyanov AV. Texture analysis and identification of the crystal lattice type in nanoscale images. Computer Optics, 2011; 35(2): 151-157. [in Russian]

92. Kupriyanov AV. Observability of a crystal lattice by multiple nodes in the images of their projections. Computer Optics, 2012; 36(4): 586-589. [in Russian]

93. Kotlyar VV, Nalimov AG, Shanina MI, Soifer VA, O'Faolain L, Mineyev EV, Yakimchuk IV, Asadchikov VE. Study of focusing properties of a zone plate for hard X-rays. Computer Optics, 2012; 36(1): 65-71. [in Russian]

94. Nalimov AG, Kotlyar VV. Use of combined zone plates as imaging optics for hard xrays. Computer Optics, 2015; 39(1): 52-57. [in Russian]

95. Zhuravel YN, Fedoseev AA. The features of hyperspectral remote sensing data processing under environment monitoring tasks solution. Computer Optics, 2013; 37(4): 471-476. [in Russian]

96. Zimichev EA, Kazanskiy NL, Serafimovich PG. Spectral-spatial classification with kmeans++ particional clustering. Computer Optics, 2014; 38(2): 281-287. [in Russian]

97. Denisova AYu, Myasnikov VV. Anomaly detection for hyperspectral imaginary. Computer Optics, 2014; 38(2): 287-296. [in Russian]

98. Kazanskiy NL, Protsenko VI, Serafimovich PG. Comparison of system performance for streaming data analysis in image processing tasks by sliding window. Computer Optics, 2014; 38(4): 804-810. [in Russian]

99. Kazanskiy NL, Kharitonov SI, Khonina SN, Volotovskiy SG, Strelkov YuS. Simulation of hyperspectrometer on spectral linear variable filters. Computer Optics, 2014; 38(2): 256-270. [in Russian] 
100. Kazanskiy NL, Kharitonov SI, Karsakov AV, Khonina SN. Modeling action of a hyperspectrometer based on the offner scheme within geometric optics. Computer Optics, 2014; 38(2): 271-280. [in Russian]

101. Kazanskiy NL, Kharitonov SI, Khonina SN. Simulation of a hyperspectrometer based on linear spectral filters using vector Bessel beams. Computer Optics, 2014; 38(4): 770776. [in Russian]

102. Kazanskiy NL, Kharitonov SI, Doskolovich LL, Pavelyev AV. Modeling the performance of a spaceborne hyperspectrometer based on the Offner scheme. Computer Optics, 2015; 39(1): 70-76. [in Russian]

103. Kotlyar VV, Kovalev AA, Zaskanov SG. Two-dimensional accelerating Bessel beams. Computer Optics, 2014; 38(3): 386-392. [in Russian]

104. Kotlyar VV, Kovalev AA, Porfirev AP. Hermite-gaussian laser beams with orbital angular momentum. Computer Optics, 2014; 38(4): 651-657. [in Russian]

105. Kovalev AA, Kotlyar VV, Porfirev AP. Generation of half-Pearcey laser beams by a spatial light modulator. Computer Optics, 2014; 38(4): 658-662. [in Russian]

106. Stafeev SS, O'Faolain L, Shanina MI, Nalimov AG, Kotlyar VV. Sharp focusing of a mixture of radially and linearly polarized beams using a binary microlens. Computer Optics, 2014; 38(4): 606-613.

107. Degtyarev SA, Ustinov AV, Khonina SN. Nanofocusing by sharp edges. Computer Optics, 2014; 38(4): 629-637. [in Russian]

108. Savelyev DA, Khonina SN. Numerical analysis of subwavelength focusing using a silicon cylinder. Computer Optics, 2014; 38(4): 638-642. [in Russian]

109. Karpeev SV, Pavelyev VS, Khonina SN, Kazanskiy NL, Gavrilov AV, Eropolov VA. Fiber sensors based on transverse mode selection. Journal of Modern Optics, 2007; 54(6): 833-844.

110. Doskolovich LL, Kazanskiy NL, Khonina SN, Skidanov RV, Heikkila N, Siitonen S, Turunen J. Design and investigation of color separation diffraction gratings. Applied Optics, 2007; 46(15): 2825-2830.

111. Kazanskiy NL. Research and Education Center of Diffractive Optics. Proceedings of SPIE, 2012; 8410: 84100R. doi: 10.1117/12.923233.

112. Bykov DA, Doskolovich LL, Soifer VA, Kazanskiy NL. Extraordinary Magneto-Optical Effect of a Change in the Phase of Diffraction Orders in Dielectric Diffraction Gratings. Journal of Experimental and Theoretical Physics, 2010; 111(6): 967-974. doi:10.1134/S1063776110120095.

113. Kazanskiy NL, Popov SB. Machine Vision System for Singularity Detection in Monitoring the Long Process. Optical Memory and Neural Networks (Information Optics), 2010; 19(1): 23-30. doi:10.3103/S1060992X10010042.

114. Khonina SN, Kazanskiy NL, Volotovsky SG. Influence of Vortex Transmission Phase Function on Intensity Distribution in the Focal Area of High-Aperture Focusing System. Optical Memory and Neural Networks (Information Optics), 2011; 20(1); 23-42. doi: 10.3103/S1060992X11010024.

115. Khonina SN, Kazanskii NL, Ustinov AV, Volotovskii SG. The lensacon: nonparaxial effects. Journal of Optical Technology, 2011; 78(11): 724-729. doi: 10.1364/JOT.78.000724.

116. Golovashkin DL, Kasanskiy NL. Solving Diffractive Optics Problem using Graphics Processing Units. Optical Memory and Neural Networks (Information Optics), 2011; 20(2): 85-89. doi:10.1134/S1063776110120095.

117. Bezus EA, Doskolovich LL, Kazanskiy NL. Scattering suppression in plasmonic optics using a simple two-layer dielectric structure. Applied Physics Letters, 2011; 98(22): 221108. doi: 10.1063/1.3597620. 
118. Bezus EA, Doskolovich LL, Kazanskiy NL, Soifer VA. Scattering in elements of plasmon optics suppressed by two-layer dielectric structures. Technical Physics Letters, 2011; 37(12): 1091-1095. doi: 10.1134/S1063785011120030.

119. Soifer VA. Diffractive Nanophotonics and Advanced Information Technologies. Herald of the Russian Academy of Sciences, 2014; 84(1): 9-18.

120. Khonina SN, Savelyev DA, Kazanskiy NL. Vortex phase elements as detectors of polarization state. Optics Express, 2015; 23(14): 17845-17859. doi: 10.1364/OE.23.017845.

121. Kazanskiy NL. A research complex for solving problems of computer optics. Computer Optics, 2006; 29: 58-77. [in Russian]

122. Kazanskiy NL, Murzin SP, Tregub VI, Mezhenin AV. Application of a focusator radiation for generating nanoporous structures of crystalline materials. Computer Optics, 2007; 31(2): 48-51. [in Russian]

123. Kazanskiy NL, Murzin SP, Mezhenin AV, Osetrov EL. Laser radiation shaping for creation nanodimensional porous structures of materials. Computer Optics, 2008; 32(3): 246-248. [in Russian]

124. Golub MA, Kazanskiy NL, Sisakyan IN, Soifer VA. Standard wavefronts formation with the computer optics elements. Computer Optics, 1990; 7: 3-26. [in Russian]

125. Kotlyar VV, Stafeev SS. Modeling the sharp focus of radially polarized laser mode with conical and binary microaxicons. Computer Optics, 2009; 33(1): 52-60. [in Russian]

126. Khonina SN, Volotovsky SG. Controlling the contribution of the electric field components to the focus of a high-aperture lens using binary phase structures. Computer Optics, 2010; 34(1): 58-68. [in Russian]

127. Zvekov AA, Kalenskii AV, Nikitin AP, Aduev BP. Radiance distribution simulation in a transparent medium with Fresnel boundaries containing aluminum nanoparticles. Computer Optics, 2014; 38(4): 749-756. [in Russian] 